\title{
THE CORRELATION BETWEEN BONE DENSITY AND IMPLANT STABILITY Youssef $\mathrm{M}^{1} B D S$, Shaaban A M ${ }^{2} P h D$, Eldibany $\mathrm{R}^{2} P h D$.
}

\begin{abstract}
:
Introduction: Long-term studies have documented the successful treatment of edentulous and partially edentulous patients with endosseous titanium implants. Success rates between $81 \%$ and $93 \%$ have been reported. Successful treatment with endosseous implants is dependent upon a complex relationship of numerous factors. Bone density and implant stability are important factors for implant osseointegration which has been widely demonstrated by several authors.

Objectives: This study was designed to evaluate the correlation between bone density estimated by Cone-Beam Computed Tomography (CBCT) and stability of dental implants estimated by resonance frequency analysis using Osstell ISQ.

Materials and methods: Ten dentis s-clean tapered implants were inserted in posterior mandibular edentulous spaces in ten adult patients. The bone density of implants recipient sites were determined by density value (HU) using CBCT. And the implants' stability were determined by quantitative unit called implant stability quotient (ISQ) measured by resonance frequency analysis using Osstell ISQ. Both values were determined immediately post-operatively and on intervals of $3 \& 6$ months.

Results: The mean implant stability value was $67.3 \pm 9.14$ immediately post-operatively, then increased on the 3 rd month to be $72.3 \pm 3.95 \& 75.2$ \pm 5.33 on the 6 th month, there was a statistical significant increase. Also the results of the present study showed that the mean bone density value was $827.96 \pm 206.85$ immediately post-operatively, then increased to $890.67 \pm 138 \& 1018.0 \pm 149.79$ on the $3^{\text {rd }}$ and $6^{\text {th }}$ months respectively, there was a statistical significant increase.

Conclusion: There was no correlation between bone density and implant stability. Keywords: bone density, implant stability, cone beam CT, resonance frequency analysis..

1- Dentist, Faculty of Dentistry, Alexandria University, Egypt.

2- Professor at Department of Oral and Maxillofacial surgery, Faculty of Dentistry, Alexandria University, Egypt.
\end{abstract}

\section{INTRODUCTION}

Osseointegrated dental implants have become an important therapeutic modality since the last decade with success rates ranging between $90 \%-95 \%$ in healthy patients. Still failures of up to $10 \%$ are still encountered. In general, these failure rates have been associated with poor bone quality and/or quantity and lack of stability of the implant (1-3).

Bone quality can improve around a functional osseointegrated dental implant due to the positive bone stimulation, the more bone that is present at an implant site, the better the possibility for implant success. Bone quality can be described by factors other than bone density such as skeletal size, the architecture and 3-dimensional orientation of the trabeculea, matrix properties, mineralization and structure $(3,4)$.

Several approaches such as densitometric measurements, dual energy X-ray absorptiometry, computerized tomography (CT) and dental cone-beam CT In the last years, cone beam computed tomography (CBCT) became widely used for oral and maxillofacial imaging providing a good spatial resolution, gray density range, and contrast, as well as a good pixel/noise ratio (5-8).

Implant stability is a combination of mechanical and biological stability; mechanical stability is the result of compression of bone tissue during implantation (primary stability), while biological stability is the result of newly formed bone cells, which are created on the implant surface during the osseointegration process (secondary stability) (9-13).
Various methods were used for implant stability testing such as histomorphologic research, tensional test, pushout/pull-out test and removal torque test, which are classified as destructive methods. Non-destructive methods include percussion test, cutting torque test while placing implants, Periotest ${ }^{\circledR}$ (Siemens AG, Benshein, Germany), and resonance frequency analysis (RFA) (14).

Resonance frequency analysis has been introduced to provide an objective measurement of implant primary stability and to monitor implant stability over the healing period using Osstell ISQ (10, 15-18).

This study was designed to evaluate the correlation between bone density estimated by Cone-Beam Computed Tomography (CBCT) and stability of dental implants estimated by resonance frequency analysis using Osstell ISQ.

\section{MATERIALS AND METHODS}

A clinical trial was conducted on ten adult patients of both sexes (6 males and 4 females) having missing mandibular posterior teeth indicated for implant rehabilitation. The patients were selected from the Out Patient Clinic of the Oral \& Maxillofacial Surgery Department, Faculty of Dentistry, Alexandria University.

The inclusion criteria of this study were; patients' age ranging from 20-50 years, adequate vertical distance between the alveolar crest and the inferior alveolar canal to accommodate a minimum $8 \mathrm{~mm}$ length implants and good 
oral hygiene. While the exclusion criteria were; inadequate interocclusal space, parafunctional habits such as bruxism and clenching, uncontrolled systemic diseases such as uncontrolled diabetes and osteoporosis, chemotherapy or radiotherapy and heavy smokers.

The dentis system implants (Dentis s-clean tapered system, Woram-Dong, Dalseo-Gu, Daegu, Korea) with different diameters $(3.7,4.1$ and $4.8 \mathrm{~mm})$ and lengths $(8,10$, 12 and $14 \mathrm{~mm}$ ) were used in this study, and Osstell ISQ was used for measurement of implant stability.

Osstell ISQ (Osstell AB, stampgatan, Goteborg, Sweden) consists of Osstell ISQ instrument, probe, charger, USB cable and test peg.

The system includes the use of a SmartPeg ${ }^{\mathrm{TM}}$ attached to the dental implant by means of an integrated screw. The SmartPeg is excited by a magnetic pulse from the measurement probe on the handheld instrument. The resonance frequency, which is the measure of implant stability, is calculated from the response signal. Results are displayed on the instrument as the implant Stability Quotient (ISQ), which is scaled from 1 to 100 . The higher the value, the more stable the implant.

All patients underwent pre-operative clinical examination: Patients' data were collected; name, gender and age, medical and dental histories were taken and the oral mucosa of the edentulous area was examined for color, texture, firmness and thickness. Also all patients underwent pre-operative panoramic radiograph examination to determine the size of the implants, their relation to adjacent structures, to measure the amount of vertical height of bone above the mandibular canal, and to evaluate the condition of bone. (Fig 1)

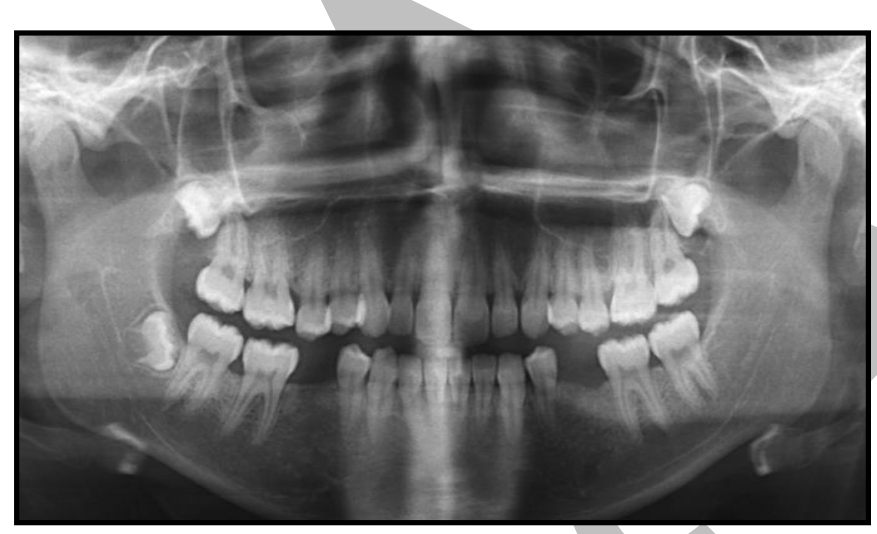

Fig. (1): Preoperative panoramic radiograph showing missing mandibular right.

Preoperative oral antibiotic one hour before surgery was given (Amoxicillin/clavulanic acid $2 \mathrm{gm}$ ) and $0.12 \%$ chlorohexidine gluconate mouth wash was used to rinse for 30 seconds before operation.

With the patient under local anesthesia a full thickness mucoperiosteal envelope flap was raised, surgical stent was fitted in the patients' mouth, osteotomy was carried out in the central part of the alveolar bone, the initial marking or preparation of the implant site was done with a pilot drill of
$2.2 \mathrm{~mm}$, the osteotomy was then widened using an intermediate drill and the final drill according to the diameter of the implant, the implant was then threaded into the bone using a Ratchet, the SmartPeg ${ }^{\text {TM }}$ was attached to the dental implant, the implant stability was measured by Osstell ISQ then the cover screw was placed, and the flap was sutured around the fixtures using 3/0 black silk suture. (Fig 2)

All patients were advised to apply cold packs extra orally intermittently every 10 minutes for 2 hours on the first day, chlorohexidine mouth wash was started on the 2nd post-operative day 3 times daily for 2 weeks, the sutures were removed after one week post surgically. Antibiotic (Amoxicillin/clavulanic acid $1 \mathrm{gm} \mathrm{tab}$ ), 2 times daily for 5 days, non-steroidal anti-inflammatory drugs (ibuprofen 400 mg , EIPICO, 10th of Ramadan city, Egypt), 3 times daily for 3 days were given.

All patients were evaluated immediately postoperatively and on intervals of $3 \& 6$ months, for presence of pain, swelling or infection using Visual Analogue Scale (VAS) (19), gingival inflammation using the Löe and Silness Gingival Index (20) on the 2nd and 7th postoperative days and implant mobility was tested according to Mickney and Koth (21), then the implant stability measurement was examined at the time of insertion and on intervals of 3 and 6 months postoperatively using the Resonance Frequency Analysis via the Osstell ISQ system.

All the implants involved in this study were radiographed by CBCT immediately post operatively and on intervals of $3 \& 6$ months to assess the bone density around the implants, exposure was performed using "veraviewepocs 3D R100" at $8 \mathrm{MA}, 90 \mathrm{KV}$ and at a proper field of view. Densitometric analysis was performed around dental implants on CBCT image at these 3 time intervals using the "Ondemand 3D"software supplied with the previously mentioned machine. This analysis gives the actual bone density around the immersed dental implant that proves the process of osseointegration. (Fig 3)

Final prosthesis (porcelain fused to metal crown) was placed after three months.

The statistical analysis was performed to evaluate the correlation between bone density values and ISQ values immediately post-operative and on intervals of 3 and 6 months.

\section{RESULTS}

Ten implants were placed in a total of ten patients (4 females and 6 males) having missing mandibular posterior teeth were included in this study. Their ages ranged between 20 and 50 years with mean age of 35 years. They were selected from the Outpatient Clinic of the Oral and Maxillofacial Surgery Department, Faculty of Dentistry, Alexandria University. All patients had undergone surgical procedures for delayed implant placement and loading. All patients were followed up both clinically and radiographically for 6 months.

All patients had been operated under local anesthesia using surgical flap technique and implant placement, and no 


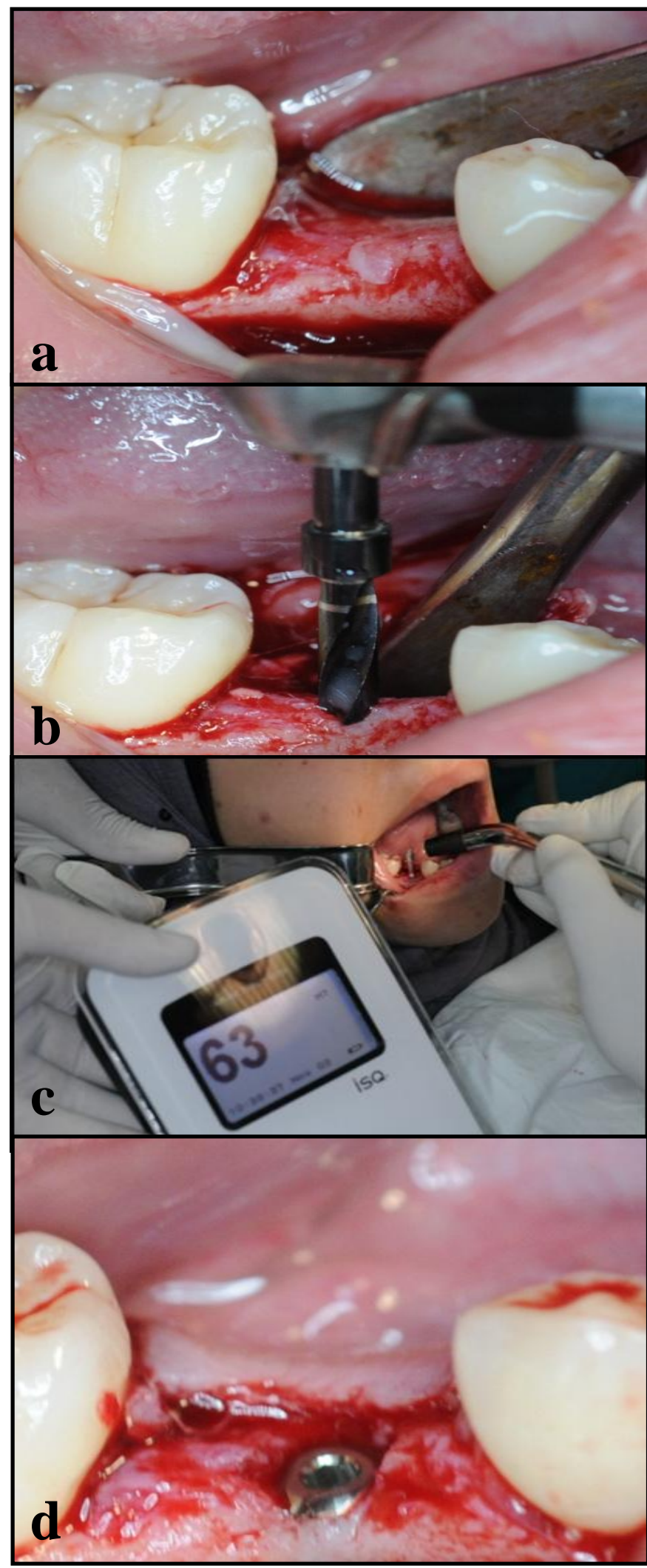

Fig. (2): A photograph showing the implant placement surgical procedures and implant stability measurement. (a) mucoperiostal envelope flap reflection. (b) intermediate drill. (c) measurement displayed on the portable instrument screen. (d) cover screw.
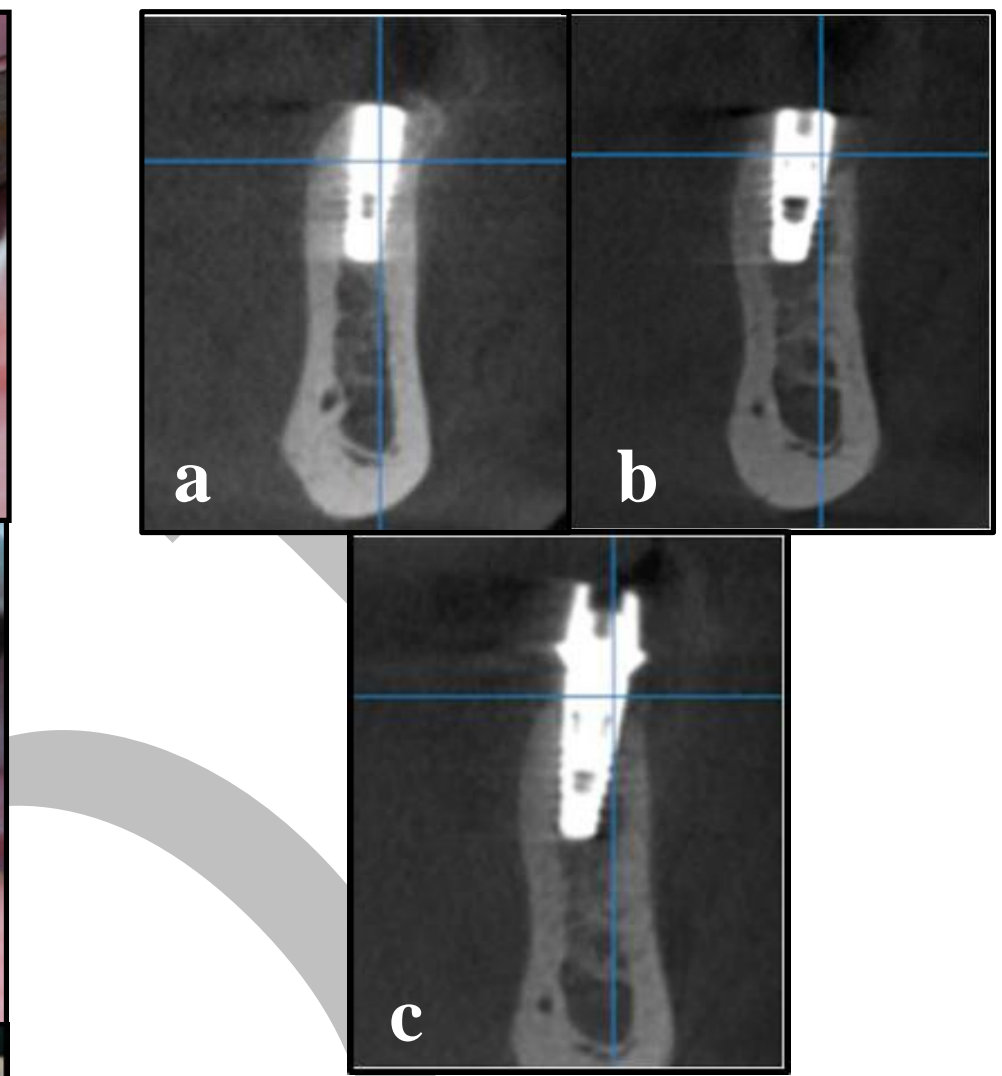

Fig. (3): CBCT image of the implant taken (a) immediately post operatively (b) $3^{\text {rd }}$ month postoperatively and (c) $6^{\text {th }}$ month postoperatively

complications had been recorded during the operation.

All patients had been examined periodically during the follow-up period up to 6 months. Healing was uneventful in all cases with no post-operative complications. Other clinical parameters had been recorded such as: Pain index, gingival index, implant mobility and Implant Stability.

1) Pain, tenderness, infection and/or swelling after surgery; all patients experienced slight to mild pain at the surgical site. Four had slight pain and showed mild oedema which subsided totally by the $2^{\text {nd }}$ post-operative day. Two others had mild pain and mild oedema which also disappeared completely by the $2^{\text {nd }}$ post-operative day. Four patients experienced mild pain and moderate edema, which subsided totally by the $4^{\text {th }}$ post-operative day. All patients continued the follow up period without any signs of infection, gingivitis, or peri-implantitis.

2) Gingival Index; no signs of gingival inflammation were observed in all patients. (i.e. gingival index score was 0 )

3) Implant mobility; all over the evaluation period, none of the implants showed any signs of mobility (i.e. mobility score was 0 ).

4) Implant Stability Evaluation; immediately postoperative, the mean implant stability value was $67.3 \pm 9.14$ (that value is known as primary stability) with a minimum recorded value of 56.0 and a maximum recorded value of 83.0. On the third month, the mean implant stability value was $72.3 \pm 3.95$ with a minimum recorded value of 65.0 and 
a maximum recorded value of 78.0. On the sixth month, the mean implant stability value was $75.2 \pm 5.33$ with a minimum recorded value of 63.0 and a maximum recorded value of 81.0 .

The mean implant stability on the 3rd postoperative month showed no significant difference when compared with the immediate postoperative measurements $(\mathrm{p}=0.06)$. While, the mean implant stability was statistically significant on the $6^{\text {th }}$ month postoperatively when compared with the immediate postoperative measurements $(p=0.01)$. Also, the mean implant stability was statistically significant on the $6^{\text {th }}$ month postoperatively when compared with the $3^{\text {rd }}$ month postoperative measurements $(p=0.01)$. (Table 1, Fig 4)
On the sixth month, the mean peri-implant bone density value for the study group was $1018.0 \pm 149.79$ with a minimum recorded value of 805.85 and a maximum recorded value of 1218.14 .

The mean bone density on the $3^{\text {rd }}$ postoperative month showed no significant difference when compared with the immediate postoperative measurements $(\mathrm{p}=0.151)$. While, the mean bone density was statistically significant on the 6th month postoperatively when compared to the immediate postoperative measurements $(p<0.001)$. Also, the mean bone density was statistically significant on the $6^{\text {th }}$ month postoperatively when compared with the $3^{\text {rd }}$ month postoperative measurements $(\mathrm{p}=0.001)$. (Table 2, Fig 5)

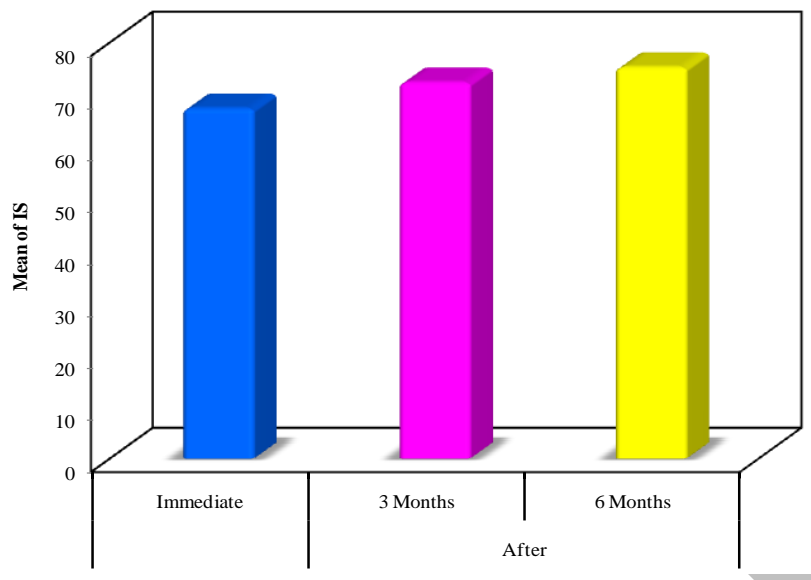

Fig. (4): Comparison between the different studied periods according to implant stability.

\begin{tabular}{|c|c|c|c|}
\hline & & \multicolumn{2}{|c|}{ After } \\
\cline { 3 - 4 } & Immediate & 3 Months & 6 Months \\
\hline IS & & & \\
Min. - Max. & $56.0-83.0$ & $65.0-78.0$ & $63.0-81.0$ \\
Mean \pm SD. & $67.30 \pm 9.14$ & $72.30 \pm 3.95$ & $75.20 \pm 5.33$ \\
Median & 66.50 & 72.50 & 76.50 \\
\hline p1 & & 0.064 & $0.014 *$ \\
\hline p2 & & & $0.012 *$ \\
\hline
\end{tabular}

Table (1): Comparison between the different studied periods according to implant stability.

p1: $\mathrm{P}$ value for paired t-test for comparing between immediate post-operative period and after 3 months and 6 months.

p2: $\mathrm{P}$ value for paired t-test for comparing between $3^{\text {rd }}$ and $6^{\text {th }}$ months post-operatively.

*: Statistically significant at $\mathrm{p} \leq 0.05$.

5) Radiographic evaluation; evaluation of bone density around the implants immediately post-operative, the mean peri-implant bone density value was $827.96 \pm 206.85$ with a minimum recorded value of 573.42 and a maximum recorded value of 1174.53 .

On the third month, the mean peri-implant bone density value was $890.67 \pm 138.31$ with a minimum recorded value of 715.38 and a maximum recorded value of 1123.0.

\begin{tabular}{|c|c|c|c|}
\hline & \multirow{2}{*}{ Immediate } & \multicolumn{2}{|c|}{ After } \\
\cline { 3 - 4 } & & 3 Months & 6 Months \\
\hline BD & $573.42-1174.53$ & $715.38-1123.0$ & $805.85 \pm 1218.14$ \\
Min. - Max. & $827.96 \pm 206.85$ & $890.67 \pm 138.31$ & $1018.0 \pm 149.79$ \\
Mean \pm SD. & 817.01 & 857.22 & 1017.25 \\
Median & & 0.151 & $<0.001^{*}$ \\
\hline p1 & & & $0.001^{*}$ \\
\hline p2 & & & \\
\hline
\end{tabular}

Table (2): Comparison between the different studied periods according to bone density

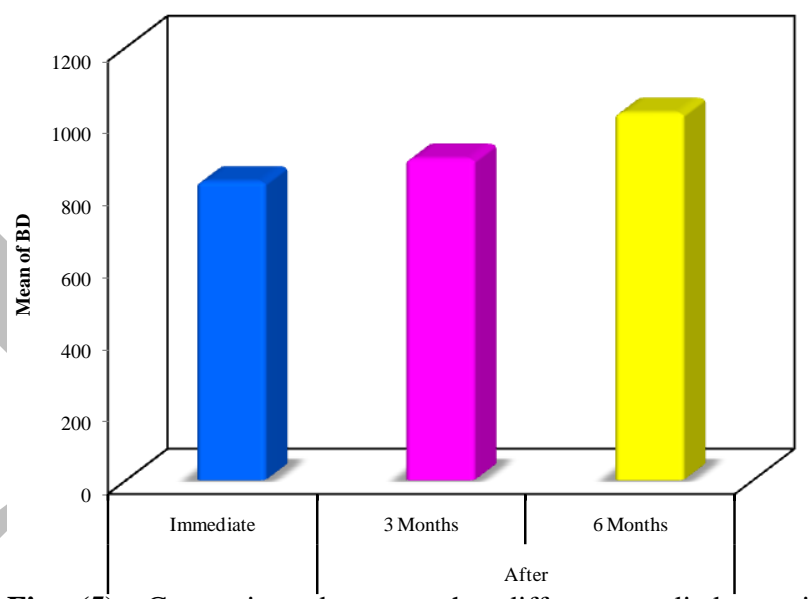

Fig. (5): Comparison between the different studied periods according to bone density

Correlation between implant stability and bone density: The analysis of the effect of bone density on the implant stability showed that there was no statistically significant relationship between the implant stability and bone density in any of the follow-up periods $(\mathrm{p}=0.62, \mathrm{p}=0.19, \mathrm{p}=0.37)$. (Table 3)

\section{DISCUSSION}

The successful treatment of dental implants depends on the concept of osseointegration introduced by Branemark which implies the structural and functional contact between the implant and the surrounding vital bone (22). Bone density and implant stability are important factors for implant osseointegration which has been widely demonstrated by several authors (23). 


\begin{tabular}{|l|l|l|}
\hline \multirow{2}{*}{} & \multicolumn{2}{|c|}{ BD vs IS } \\
\cline { 2 - 3 } & r & p \\
\hline Immediate & -0.179 & 0.620 \\
\hline 6 Months & -0.446 & 0.196 \\
\hline
\end{tabular}

Table (3): Correlation between Bone density and implant stability. r: Pearson coefficient *: Statistically significant at $p \leq 0.05$ BD: Bone density

Therefore, the present study was designed to evaluate the correlation between the bone density and the stability of dental implants in the posterior region of the mandible.

In this study 10 patients with missing mandibular posterior teeth were selected from the Outpatient Clinic of the Oral and Maxillofacial Surgery Department, Faculty of Dentistry, Alexandria University. The selected patients were free from any uncontrolled systemic diseases or conditions that may complicate the surgical procedure or the healing process of the implant. This was following a study performed by Bornstein et al in 2009 (24) where they reviewed whether systemic diseases with/without systemic medications increased the risk of implant failure and therefore diminish the success and survival rates of dental implants. They stated that the level of evidence indicative of absolute and relative contraindications for implant therapy due to systemic diseases is low.

CBCT was used to measure the bone density because of its accuracy, lower radiation exposure and fewer cost compared with CT .This was following a study performed by Cassetta et al in 2014 (25) where they scanned twenty dry mandibles with CBCT and conventional CT to evaluate if there is a statistically significant difference between the bone density values they produce, defined as gray density values and to determine any correlation between them. They concluded that the lower radiation dose and reduced costs of CBCT make this a useful substitute for CT, however, they stated that in order to more accurately define the bone density with CBCT, a conversion ratio needs to be applied to the voxel value.

In this study, the mean bone density increased significantly towards the $6^{\text {th }}$ month post-operative. This can be attributed to the healing of the bone around implants.

These results were in agreement with the results of $\mathrm{Al}-$ Sudani in 2014 (26). In her study, twenty implants in the premolar and molar regions of upper and lower jaws were evaluated using CT scan to measure the bone density by using HU around dental implants and after six months after dental implant placement. The mean $\mathrm{HU}$ of jaw bone immediately following implant placement was $552.28 \mathrm{HU}$ and increased significantly to $761.33 \mathrm{HU}$ after six months statistically.

Implant stability was measured using the Resonance Frequency Analysis (RFA) via the Osstell ISQ system. RFA was chosen as a noninvasive and reliable method to assess variation in implant stability over time. RFA registrations are directly related to the stability of the implant in the surrounding bone: during healing an increase in implant stability quotient (ISQ) values presumably reflect new bone apposition at the implant-bone interface (15, 27-31).

Meredith et al $(15,32)$ concluded that RFA is a method that can serve as a useful research technique and it is valuable in studying the behavior of implants in surrounding tissue. Also, Jaramillo et al in 2014 (33) reported that Resonance frequency analysis systems in Osstell Mentor and Osstell ISQ show almost perfect reproducibility, repeatability and accuracy.

In this study the mean implant stability value was 67.3 \pm 9.14 immediately post-operatively, then increased on the 3 rd month to be $72.3 \pm 3.95 \& 75.2 \pm 5.33$ on the $6^{\text {th }}$ month there was a statistical significant increase.

These results are in agreement with Huwiler et al in 2007 (34), where they studied the resonance frequency analysis (RFA) during the early phases of healing. They concluded that during the incorporation and healing phase of the implants, the mean values for the various observation periods the ISQ values seemed to increase.

Also, the surface treatment of the implant had a role in the increase of the ISQ value in the present study during the healing period. All the implants placed are resorbable blast media (RBM) treated, in which the surface of the implant is blasted with calcium phosphate powder in order to increase cohesion of bone tissue, followed by thorough cleaning of the surface.

This is accordance with Glauser et al in 2007 (35), where they reported that implant design and surface treatment have a significant influence on soft bone.

Also, this is agreement with Kim et al in 2010 (36) where they evaluated the effects of different implant surface treatments on implant stability in dog mandibles. A total of 30 implants were placed in 5 dog mandibles. Bone quality was assessed at each site. An Osstell resonance frequency analyzer (RFA) was used to determine the stability at different periods after surgery. The results of this study suggested that surface treatments may have significant effects on the biological stability.

In this study, the analysis of the effect of bone density on the implant stability showed that there was no statistically significant relationship between these two factors throughout the study period.

These findings agreed with the results of Huwiler et al in 2007 (34), when analyzing the morphologic characteristics of the parent bone into which the implants were placed, no correlations could be demonstrated between the ISQ values and the bone volume density and/or the bone trabecular connectivity as revealed by micro CT analysis of bone cores obtained at the time of implant installation

Moreover, Farre- Pages et al in 2010 (37), studied the relation between the bone quality and primary stability and they concluded that there was no relation between the ISQ value and bone quality.

On the other hand, Turkyilmaz et al in 2007 (38) reported that the bone density value from pre-operative CT examination may provide an objective assessment of bone quality and significant correlations between bone density and implant stability parameters may help clinician to predict primary stability before implant insertion. 
Also, Sumera et al in 2013 (39) stated that positive correlation between RFA values and bone density was found for all four regions of the jaws.

Moreover, Salimov et al in 2014 (40) reported that bone density assessment using CBCT is an efficient method and significantly correlated with implant stability parameters and Lekholm and Zarb index. Thus, it is possible to predict initial implant stability and possibility of immediate or early loading using CBCT scans prior to implant placement.

The contradiction between the results of the above studies and this study may be attributed to the use of a higher number of implants with minimum 57 implants, but in this study only 10 implants were used. Also, in their studies they used more than one type of bone according to Lekholm and Zarb classification, but in this study only one region of the mandible was selected. In addition, in their studies they correlated the bone density with primary stability only, but in this study we correlated the bone density with primary implant stability and secondary implant stability on intervals of 3 and 6 months.

\section{CONCLUSIONS}

There is no correlation between bone density and implant stability, using cone beam computed tomography is a simple method to measure bone density around dental implants and evaluate the condition of bone before implant placement and resonance frequency analysis is a reliable method to predict bone healing around implants and to measure implant stability throughout the follow up period. There is no correlation between bone density and implant stability.

\section{CONFLICT OF INTEREST}

The authors declare that they have no conflicts of interest

\section{INFORMED CONSENT}

Appropriate institutional ethical clearance and written informed consent were obtained.

\section{REFERENCES}

1. Att W, Stappert C. Implant therapy to improve quality of life. Quintessence Int 2003; 34: 8: 573-81.

2. Vidyasagar L, Apse P. Dental implant design and biological effects on bone-implant interface. Stomatologija 2004; 6: 51-4.

3. Gulsahi A. Bone quality assessment for dental implants. Rijeka: InTech 2011: 437-52.

4. Marquezan M, Osório A, Sant'Anna E, Souza MM, Maia L. Does bone mineral density influence the primary stability of dental im $\neg$ plants? A systematic review. Clin Oral Implants Res 2012; 23: 767-74.

5. Arisan V, Karabuda ZC, Avsever H, Özdemir T. Conventional multi-slice computed tomography (CT) and cone-beam CT (CBCT) for computer assisted implant placement. Part I: relationship of radiographic gray density and implant stability. Clin Implant Dent Relat Res 2013; 15: 893-906.

6. Cassetta M, Tarantino F, Calasso S. Conservative treatment of odontogenic keratocyst: A case report and review of the literature. Dental Cadmos 2009; 77: 19-40.

7. Calasso S, Cassetta M, Galluccio G, Barbato E. Impacted lower second molars. Dental Cadmos 2008; 76:41-54.

8. Cassetta M, Tarantino F, Calasso S. CAD-CAM systems in titanium customized abutment construction. Dental Cadmos 2010; 78: 27-44.

9. Sennerby L, Meredith N. Resonance frequency analysis: measuring implant stability and osseointegration. Compend Contin Educ Dent 1998; 19: 493-8.

10. Friberg B, Sennerby L, Linden B, Grondahl K, Lekholm $\mathrm{U}$. Stability measurements of one-stage Branemark implants during healing in mandibles. A clinical resonance frequency analysis study. Int $\mathrm{J}$ Oral Maxillofac Surg 1999; 28: 266-72.

11. Sunden S, Grondahl K, Grondahl HG. Accuracy and precision in the radiographic diagnosis of clinical instability in Branemark dental implants. Clin Oral Implants Res 1995; 6: 220-6.

12. Quesada-Garcia MP, Prados-Sanchez E, Olmedo-Gaya MV, Munoz-Soto E, Gonzalez-Rodriguez MP, Vallecillo-Capilla M. Measurement of dental implant stability by resonance frequency analysis: A review of the literature. Med Oral Patol Oral Cir Bucal 2009; 14: 538-46.

13. Esposito M, Hirsch $\mathrm{J}$, Lekholm U, Thomsen $\mathrm{P}$. Biological factors contributing to failures of osseointegrated oral implants, (I). Success criteria and epidemiology. Eur J Oral Sci 1998; 106: 527-51.

14. Meredith N. Assessment of implant stability as a prognostic determinant. Int J Prosthodont 1998; 11:491-501.

15. Meredith N, Book K, Friberg B, Jemt T, Sennerby L. Resonance frequency measurements of implant stability in vivo. A crosssectional and longitudinal study of resonance frequency measurements on implants in the edentulous and partially dentate maxilla. Clin Oral Implants Res 1997; 8: 226-333.

16. Meredith N, Shagaldi F, Alleyne D, Sennerby L, Cawley $P$. The application of resonance frequency measurements to study the stability of titanium implants during healing in the rabbit tibia. Clin Oral Implants Res 1997; 8: 23443.

17. Rasmusson L, Kahnberg KE, Tan A. Effects of implant design and surface on bone regeneration and implant stability: an experimental study in the dog mandible. Clin Implant Dent Relat Res 2001; 3: 2-8.

18. Bischof M, Nedir R, Szmukler-Moncler S, Bernard JP, Samson J. Implant stability measurement of delayed and immediately loaded implants during healing. Clin Oral Implants Res 2004; 15: 529-39

19. Boonstra AM, Schiphorst Preuper HR, Reneman MF, Posthumus JB, Stewart RE. Reliability and validity of the visual analogue scale for disability in patients with chronic musculoskeletal pain. Int J Rehabil Res 2008; 31: 165-9.

20. McClanahan SF, Bartizek RD, Biesbrock AR. Identification and consequences of distinct Löe-Silness gingival index examiner styles for the clinical assessment of gingivitis. J Periodontol 2001; 72: 383-92. 
21. Steflik D, Koth DL, Robinson F, McKinney R, Davis B, Morris C, et al. Prospective investigation of the singlecrystal sapphire endosteal dental implant in humans: Ten-year results. J Oral Implantol 1995; 21: 8-18.

22. Adell R, Lekholm U, Rockler B, Branmark PI. A 15year study of osseointegrated implant in treatment of the edentulous jaw. Int J Oral surgery 1981; 10: 387- 416.

23. Molly L. Bone density and primary stability in implant therapy. Clin Oral Implants Res 2006; 17: 124-35.

24. Bornstein MM, Cionca N, Mombelli A. Systemic conditions and treatments as risks for implant therapy. Int J Oral Maxillofac Implants. 2009; 24: 12-27.

25. Cassetta M, Stefanelli LV, Pacifici A, Pacifici L, Barbato E. How accurate is CBCT in measuring bone density? A comparative CBCT-CT in vitro study. Clin Implant Dent Relat Res 2014; 16: 471-8.

26. Al-Sudani RJ. Assessment of bone density after six months from dental implants placement using Computed Tomography. J Bagh Coll Dentistry 2014; 26: 126-8.

27. Sim CP, Lang NP. Factors influencing resonance frequency analysis assessed by Osstell mentor during implant tissue integration: I. Instrument positioning, bone structure, implant length. Clin Oral Implants Res 2010; 21: 598-604.

28. Kessler-Liechti G, Zix J, Mericske-Stern R. Stability measurements of 1-stage implants in the edentulous mandible by means of resonance frequency analysis. Int J Oral Maxillofac Implants 2008; 23: 353-8.

29. Cocharan DL, Schenk RK, Lussi A, Higginbottom FL, Buser D. Bone response to unloaded and loaded titanium implants with a sandblasted and acid-etched surface: A histometric study in the canine mandible. J Biomed Mater Res 1998; 40: 1-11.

30. Brunski JB. Biomechanical factors affecting the bonedental implant interface. Clin Mater 1992; 10: 153-201.

31. Davies JE. Mechanisms of endosseous integration. Int J Prosthodont 1998; 11: 391-401.

32. Meredith N, Alleyne D, Cawley P. Quantitative determination of the stability of the implant-tissue interface using resonance frequency analysis. Clin Oral Implants Res 1996; 7: 261-7.

33. Jaramillo R, Santos R, Lázaro P, Romero M, RiosSantos JV, Bullón P, et al. Comparative analysis of 2 resonance frequency measurement devices: Osstell Mentor and Osstell ISQ. J Implant Dent 2014; 23: 3516.

34. Huwiler MA, Pjetursson BE, Bosshardt DD, Salvi GE, Lang NP. Resonance frequency analysis in relation to jawbone characteristics and during early healing of implant installation. Clin Oral Implants Res 2007; 18: 275-80.

35. Glauser R, Zembic A, Ruhstaller P, Windisch S. Fiveyear results of implants with an oxidized surface placed predominantly in soft quality bone and subjected to immediate occlusal loading. J Prosthet Dent 2007; 97: S5968.

36. Kim SJ, Kim MR, Rim JS, Chung SM, Shin SW. Comparison of implant stability after different implant surface treatments in dog bone. J Appl Oral Sci 2010; 18: 415-20.

37. Farré-Pagés N, Augé-Castro ML, Alaejos-Algarra F, Mareque-Bueno J, Ferrés-Padró E, Hernández-Alfaro F. Relation between bone density and primary implant stability. Med Oral Patol Oral Cir Bucal 2010; 16: e62-7.

38. Turkyilmaz I, Tumer C, Ozbek EN, Tözüm TF. Relations between the bone density values from computerized tomography, and implant stability parameters: a clinical study of 230 regular platform implants J Clin Periodontol 2007; 34: 716-22.

39. Sumera P, Danacib M, Telciogluc NT, Sandikcic EO, Sumerd M, Gulere AU. Assessment of the correlation between bone density and implant stability. J Exp Clin Med 2013; 30: 237-40.

40. Salimov F, Tatli U, Kürkçü M, Akoğlan M, Oztunç H, Kurtoğlu C. Evaluation of relationship between preoperative bone density values derived from cone beam computed tomography and implant stability parameters: a clinical study. Clin Oral Implants Res 2014; 25 : 1016-21. 